\title{
Educação, escola e humanização em Marx, Engels e Lukács
}

\author{
Liliam Faria Porto Borges \\ Universidade Estadual do Oeste do Paraná
}

\section{Resumo}

Otrabalho discute o entendimento da escola a partir dos conceitos de trabatho e humanização em Marx, Engels e Lukács. A constituição humana por meio da sua intervenção junto à natureza e o estabelecimento das relações sociais são processos educativos que se repetem, tanto na história do homem, quanto no desenvolvimento individual, recolocando, nos processos educativos, a construção do homem como ser social e construindo o longo caminho de distanciamento de sua condição animal. Com base nesse breve panorama, propõe uma análise acerca da escola e do ensino no Brasil, indicando a função social da educação escolar e o significado das perspectivas pedagógicas que secundarizam a relação entre ensinar e aprender.

Palavras-chave: Educação. Escola. Humanização.

\section{Education, school and humanization in Marx, Engels and Lukács}

\section{Abstract}

The paper discusses the education and school understanding from the working concepts and humanization on Marx, Engels and Lukács. The human constitution through its intervention with nature and the establishment of the social relations are instructional processes that are repeated both in the history of man and in the individual development, replacing in the instructional processes the construction of man, as social being and building the long distance path of his animal condition. From this such brief panorama, the text proposes an analysis about school and teaching in Brazil indicating the social role of the education at school and the meaning of the pedagogical perspectives that put into second place the relationship between teaching and learning.

Keywords: Education. School. Humanization. 


\section{Educación, escuela y humanización en Marx, Engels y Lukács}

\section{Resumen}

El trabajo discute el entendimiento de la educación y de la escuela a partir de conceptos de trabajo y humanización en Marx, Engels y Lukács. La constitución humana por medio de su intervención junto a la naturaleza y el asentamiento de las relaciones sociales son procesos educativos que se repiten, tanto en la historia del hombre, como en el desarrollo individual, reemplazando, en los procesos educativos, la construcción del hombre como ser social y construyendo el largo camino de alejamiento de su condición animal. A partir de ese breve panorama, se propone un análisis acerca de la escuela y de la enseñanza en Brasil, que demuestra la función social de la educación escolar y el significado de las perspectivas pedagógicas que ponen en segundo plano la relación entre enseñar y aprender. Palabras clave: Educación. Escuela. Humanización.

\section{Humanização e trabalho}

$102 \bigcirc$ planeta Terra, em sua estrutura, é composto por elementos com e sem vida - minerais, vegetais e animais. Sobre essa base natural, ergueu-se o mundo humano e, a partir dessa mesma natureza, inclui-se o Homem como ser natural, como animal. Ocorre que, ao interagir de forma determinada com a natureza, o homem foi capaz de se diferenciar do mundo natural e, em paralelo, criar outro mundo, ou seja, o mundo da cultura, o mundo humano.

Compreender essa diferenciação da natureza - na medida em que o homem se distancia de sua determinação natural, sem nunca a abandonar - é conceber a ontologia do ser social, como formulou György Lukács, com base em Karl Marx e Friedrich Engels.

Assim como todos os seres vivos, em particular os animais, interagem com a natureza para garantir sua sobrevivência, o homem, como um desses, passa a construir formas dessa interação que permitem transformações cruciais a ponto de alcançar a consciência. Com base na ação consciente, é possível compreender de que forma tal ação, antes natural, torna-se ação social, o trabalho. 
Engels (1986) afirma que o trabalho produz o homem e demonstra essa afirmação de forma analítica, considerando, sobretudo, a produção de Darwin'. O autor expõe como o homem se diferencia dos outros animais ao ter uma transformação estrutural de sua mão em determinada condição histórica e, a partir daí, o longo caminho até a utilização consciente do gesto - e a teleologia da ação - como trabalho. Esse permite uma ação cada vez mais coletiva e articulada entre os homens, que vai exigir a linguagem, consequentemente, o caminho do desenvolvimento humano na natureza e no mundo humano como ser social.

A essa grande alteração, Lukács (1978) chama "Salto Ontológico". Reafirma, apoiado nos estudos de Marx, que um ser social se desenvolve tendo por base um ser orgânico e esse também o faz a partir de um ser inorgânico, em um movimento em que o novo nasce do velho, mas de forma tão mais complexa que não mais se identifica com sua origem. Portanto, caracteriza um "salto" já que produziu elementos tão próprios na sua complexidade, configurando absolutamente novo².

Como ontologia do ser social, portanto, aquilo que define o homem como ser, para além do mundo natural, é o trabalho.

Toda riqueza provém do trabalho, asseguram os economistas. E assim o é na realidade: a natureza proporciona os matérias que o trabalho transforma em riqueza. Mas o trabalho é muito mais que isso: é o fundamento da vida humana. Podemos até afirmar que, sob determinado aspecto, o trabalho criou o próprio homem (ENGELS, 1986, p. 19).

trabalho é a forma específica e determinada pela qual os homens respondem às suas necessidades individuais e coletivas em uma cadeia de mediações que, ao se constituir, cria necessidades com o desenvolvimento de instrumentos, ferramentas, procedimentos e, sobretudo, como já foi dito, a comunicação e o desenvolvimento da linguagem. Além da atividade de alguns animais, extremamente complexa e elaborada como a construção da casa do pássaro joão de barro, do dique do castor ou da organização coletiva das abelhas e formigas, é a consciência da ação que diferencia o trabalho como algo especificamente humano.

A essência do trabalho consiste precisamente em ir além dessa fixação dos seres vivos na competição biológica com seu mundo 
ambiente. $\bigcirc$ momento essencialmente separatório é constituído não pela fabricação de produtos, mas pelo papel da consciência, a qual, precisamente aqui, deixa de ser mero epifenômeno da reprodução biológica: o produto, diz Marx, é um resultado que no início do processo existia 'já na representação do trabalhador', isto é, de modo ideal (LUKÁCS, 1978, p. 5).

E a origem dessa formulação em Marx:

Antes de tudo, o trabalho é um processo de que participam o homem e a Natureza, processo em que o homem, por sua própria ação, media, regula e controla seu metabolismo com a natureza. Ele mesmo se defronta com a matéria natural como uma força natural. Ele põem em movimento as forças naturais pertencentes à sua corporalidade, braços e pernas, cabeça e mão, a fim de apropriar-se da matéria natural numa forma útil para sua própria vida. Ao atuar, por meio desse movimento, sobre a Natureza externa a ele e ao modifica-la, ele modifica, ao mesmo tempo, sua própria natureza. Ele desenvolve as potências nela adormecidas e sujeitao jogo de suas forças ao seu próprio domínio. [...]. Pressupomos o trabalho numa forma em que pertence exclusivamente ao homem. Uma aranha executa operações semelhantes às do tecelão, e a abelha envergonha mais de um arquiteto humano com a construção dos favos de sua colmeia. Mas, o que distingue, de antemão, o pior arquiteto da melhor abelha é que ele construiu o favo em sua cabeça, antes de construílo em cera. No fim do processo do trabalho obtém-se um resultado que já no início deste existiu na imaginação do trabalhador, e portanto idealmente (MARX, 1988, p. 142).

A especificidade do trabalho seria o "pôr teleológico" nos dizeres de Lukács que revela a constituição de um novo ser que projeta em pensamento o que deverá realizar na intervenção no mundo real e cria inúmeras mediações para tal realização no mesmo movimento em que o mesmo cria variadas condições dessa realização, a fim de produzir a tal cadeia de mediações. Assim, desenvolve o que se chama de ciência, tecnologia e arte - pura formulação humana decorrente de sua atividade ontológica.

A busca por responder às necessidades inicialmente biológicas e, depois, culturais é que leva o homem a construir a ideia de algo a se efetivar. Para tal realização, é forçoso construir em pensamento os meios pelos quais 
poderá realizá-la e ideias sobre como construir as ferramentas para efetivar seu projeto e, ainda, as formas de utilização dessas. E nesse emaranhado, a consciência vai produzindo o homem e a enormidade do mundo humano - cada vez mais afastado da natureza, inclusive em suas necessidades.

\section{Educar para Humanizar}

desenvolvimento do homem no tempo e no espaço, como resultado do trabalho, produziu as variadas formações históricas e culturais que não permitiriam identificar, nos dias de hoje, as necessidades básicas humanas sem fazer menção à determinada cultura. A constituição de variadas organizações sociais determina não apenas as mais diversas formas de definição das necessidades biológicas e culturais, mas também a forma como essas se concretizam.

Produtor de necessidades e motor da cadeia de mediações, o trabatho é histórico e, diferente das abelhas; os homens não nascem aptos a ele. Além das necessidades biológicas básicas, tudo o mais, ou seja, tudo o que se constitui, além do animal humano, é transmitido nas relações sociais. $\bigcirc$ homem nasce bicho e se faz homem nas relações sociais em que se encontra. Ainda a fome e o instinto reprodutor se darão no homem, determinados pela sua forma social e cultural. E o que parece ser puro instinto se veste de determinações da cultura a ponto de machos e fêmeas não se atraírem por ser da mesma família - ou determinada carne não ser considerada alimento em um grupo carnívoro.

Nesse mundo humano, não há determinação genética que constitua relações, mas práticas que são vivenciadas e reproduzidas, portanto, aprendidas. O homem deve aprender a ser homem ou não o será. São as apropriações de suas relações sociais que o fazem ser um cavaleiro medieval ou um professor contemporâneo. Assim, a educação é ontologia humana como parte decorrente do trabalho humano.

exercício hipotético do conto acerca do menino lobo de Kipling $(2005)^{3}$ permite compreender que não há determinação prévia acerca dos elementos humanizados a não ser a vida social e suas relações, a práxis humana. É na inserção real que nos conformamos à humanidade que nos parece anterior ou predeterminada, ou causal ou como queiram as perspectivas idealistas em suas mais diversas expressões. Assim, educar é humanizar, na medida em que, ao se apropriar daquilo que os homens produziram por meio do trabalho, 
os homens são constituídos e se afastam dos animais. Humanização, nesse sentido, se remete ao afastamento da determinação natural. Se o que caracteriza o trabalho é a sua âncora teleológica, consequentemente, a consciência passa a ser também determinada pelo entorno histórico e social em que o sujeito está inserido.

Esse aparente contraditório é o movimento dialético e multideterminado que define o ser social. A partir da forma como se aprende a ser homem, ou seja, da forma social que determina a consciência, determinam-se - ao mesmo tempo - as formas de consciência com as quais será produzido o mundo onde se vive.

modo pelo qual os homens produzem os seus meios de vida depende, antes de tudo, da natureza dos meios de vida já encontrados e que tem de reproduzir. Não se deve considerar tal modo de produção de um único ponto de vista, a saber: a reprodução da existência física dos indivíduos. Trata-se, muito mais, de uma determinada forma de atividade dos indivíduos, determinada forma de manifestar sua vida, determinado modo de vida dos mesmos. Tal como os indivíduos manifestam sua vida, assim são eles. O que eles são coincide, portanto, com sua produção, tanto com o que produzem, como com o modo como produzem. O que os indivíduos são, portanto, depende das condições materiais de sua produção (MARX; ENGELS, 1984, p.27).

Além de individualmente os seres humanos serem determinados, como ser social determinam-se as relações sociais e vale reafirmar a dimensão necessariamente social do homem. José Paulo Netto e Marcelo Braz (2006) assim definem essa relação entre o ser individual e a sociedade em que está imerso e as múltiplas determinações de lado a lado.

A sociedade não é simplesmente o agregado dos homens e mulheres que a constituem, não é um somatório deles, nem algo que paira acima deles; por outro lado, os membros da sociedade não átomos, nem mônadas, que reproduziram a sociedade em miniatura. Não se pode separar a sociedade dos seus membros: não há sociedade sem que estejam em interação os seus membros singulares, assim como não há seres sociais singulares (homens e mulheres) isolados, fora do sistema de relações que é a sociedade. O que chamamos de sociedade são os modos de existir do ser social; é na sociedade e nos membros que a compõem que o ser social 
existe: a sociedade, e seus membros, constitui o ser social e dele se constitui (PAULO NETTO; BRAZ, 2006, p. 37).

Considerando as colocações acerca da concepção de homem, trabalho e ser social - e indicado o lugar da educação no processo humanizador do homem, importa discutir a concepção de desenvolvimento inerente à concepção de educação.

A concepção de desenvolvimento, fortemente marcada pelo pensamento positivista revigorado no neopositivismo e suas vertentes, remete à ideia de linearidade e progresso, de etnocentrismo e evolucionismo. Newton Duarte (2012) trata dessa questão ao recuperar os estudos de Lukács ${ }^{4}$ acerca da estética e ajuda a compreender que, no percurso histórico da humanização - do distanciamento do mundo natural - há um movimento de acúmulo, ainda que esse movimento não seja linear, tampouco homogêneo. Na complexa tensão entre humanização e alienação própria da lógica da organização das sociedades em classes sociais, em que se constituem processos de desumanização bastante profundos, a possibilidade humana de complexificar a consciência e o pensamento na elaboração da tecnologia, da ciência, sobretudo das artes (objeto de análise de Lukács) é inalienável ao gênero humano e possibilitadora de ampliação da humanização, conforme Mucci (1997).

As elaborações do pensamento que conseguem compreender a realidade e seus elementos estruturantes, de forma mais próxima do que a realidade concreta se apresenta, permitem o que seria denominado de aproximação da essência do real. Tais elaborações ainda que não se insiram na vida cotidiana da maioria dos homens - por conta da alienação e expropriação da riqueza por eles produzida - redimensionam a forma como se compreende o mundo e se produz a vida humana. Isso não ocorre imediata nem linearmente, mas, em um movimento bastante contraditório, e vai obrigar a reorganização da forma de ser dos homens e seu tempo. À medida que a ciência revisita a compreensão de determinada informação do real, ela também aprofunda a compreensão, supera os elementos de aparência e identifica as conexões além daquelas possíveis até determinado momento, pois ela, a ciência, reescreve, de forma mais aproximada, a verdade sobre aquele elemento. Ainda que, em alguns momentos, possa se afastar dessa verdade, o exercício mesmo da rigorosidade científica produz, de forma histórica, condições de continuar a busca 
pela compreensão do real e formular essa compreensão em pensamento, ao desvendar o mundo, a natureza e as relações sociais.

Afinal, um dos pressupostos do pensamento de Marx e Engels é a possibilidade humana de compreensão do mundo, de apreensão do ser das coisas, ou seja, da possibilidade efetiva de se chegar à verdade, entendendo-a sempre como histórica. A perspectiva materialista radical adotada por esses pensadores indica que a verdade reside na coisa, na realidade, no fato, enfim, na materialidade - e não no pensamento - ideia ou espírito. A possibilidade construída historicamente pelo homem de - pelo pensamento - identificar a realidade, não elimina o fato de que a verdade esteja sempre contida na coisa em si, e só como elaboração do pensamento e secundariamente na cabeça do homem, como ideia. Para Marx, a elaboração em pensamento da realidade material se dá como concreto pensado. Marx, na segunda tese sobre Feverbach, é bastante explícito:

A questão de saber se cabe ao pensamento humano uma verdade objetiva não é uma questão teórica, mas prática. É na práxis que o homem tem que demonstrar a verdade, isto é, a realidade e o poder, o carácter terreno do seu pensamento. A disputa sobre a realidade ou não realidade de um pensamento que se isola das práxis é uma questão puramente escolástica (MARX, 1984, p. 126).

A precedência da matéria sobre o pensamento - princípio do pensamento materialista - não desconsidera que, apesar de conter a verdade, o real não se revela de forma direta e é necessário um esforço do pensamento para a apreensão dessa verdade. A ciência é esse esforço e, por isso, precisa definir procedimentos rigorosos de validação e análise, de elaboração e reelaboração. Como tais procedimentos só podem ser adequados ao momento histórico do homem que estuda o real, as sínteses possíveis serão sempre históricas e mais ou menos próximas da verdade contida no real, sua essência. movimento histórico de perseguir tal essência não é linear, porém, atingida determinada elaboração mais adequada, abrem-se as possibilidades de novas apropriações e sínteses. Nesse sentido, há um desenvolvimento humano no conjunto histórico.

A crescente produção de necessidades inerentes à mediação do trabalho impele tal desenvolvimento. Assim, há, na formulação histórica da 
ciência, o espaço fundamental de se buscar a solução da cadeia de necessidades que o trabalho produz na história.

Durante esse longo período, de Descartes a Hegel e de Hobbes a Feverbach, os filósofos não avançaram impelidos apenas, como julgavam, pela força do pensamento puro. Ao contrário. O que, na realidade, os impelia para frente eram, principalmente, os formidáveis e cada vez mais rápidos progressos das ciências naturais e da indústria (ENGELS, s/d, p. 181).

Na história do homem, as intervenções sobre a natureza e as relações sociais produzem inumeráveis sínteses e compreensões até se chegar ao que se chama de ciência. Assim, seguimos na interlocução com as explicações construídas, a partir de revisões, da negação e superação, ou até serem abandonadas as temáticas e sínteses, recolocando as questões que a necessidade nos impõe. Embora esse movimento não seja linear, existem aproximações da compreensão do real que a práxis confirma como mais próxima e indica que se siga por ali e não por outro caminho de análise. Esse tem sido o movimento contraditório - de idas e vindas - da ciência.

Ao longo do contraditório e heterogêneo processo histórico, o gênero humano tem se enriquecido, isto é, tem adquirido forças, faculdades e necessidades qualitativamente superiores, que passam a constituir parte ineliminável do ser da humanidade no seu conjunto, ainda que, em decorrência das relações alienadas, essas novas forças, faculdades e necessidades não se efetivem na vida da maioria dos indivíduos. Em outras palavras, é preciso distinguir aquilo que deva ser suprimido no processo de superação da lógica societária comandada pelo capital daquilo que, apesar de ter surgido no interior de relações sociais alienadas, deva ser preservado por uma sociedade socialista e elevado a um nível superior de desenvolvimento (DUARTE, 2012, p. 3).

A alienação que resulta de relações históricas superáveis não compromete o caráter humanizante, efetivo e irreversível do enriquecimento ontológico do ser humano, conforme Duarte (2012). Se for feito o mesmo exercício de análise considerando as artes em vez da ciência, se terá ainda assim a possibilidade de identificar, nos mais diferentes lugares da história, momentos de elevada elaboração humana que permitem, inclusive, reconhecimento universal (e nesse sentido independente do seu tempo) de sentimentos e sensações. 
É importante pensar, pois, na escultura grega ou na pintura do renascimento ou na música clássica. Esses momentos em que a sensibilidade e o engenho humano produziram - de forma complexa e altamente elaborada - uma síntese capaz de comunicar algo, além de seu tempo histórico, inclusive, são indícios do desenvolvimento humano. Ademais, indicam um percurso de afastamento da determinação da natureza e podem inclusive sinalizar um projeto de mundo humano, como a construção de outro tipo de sociedade. Isso reforça o argumento de que não há qualquer concessão ao pressuposto positivista do desenvolvimento linear e progressivo da história.

Apresentam-se até aqui, de forma pontuada, alguns argumentos acerca da hipótese do trabalho como produtor do homem e do movimento histórico de desenvolvimento humano. Sabe-se que o homem faz escolhas na construção da história, visto que é determinado como ser social pelas suas condições históricas e, sobretudo, sujeito dessa mesma história; assim, deve-se pensar, a partir de agora, no papel da educação nesse processo humanizador.

\section{Educação e saberes escolares}

110 processo educativo é humanizador na medida em que permite que os seres humanos desenvolvam sua capacidade ontológica. Se o Homem é ser social, portanto, ao mesmo tempo, natureza e cultura, toda ampla dimensão não natural deve ser adquirida nas relações sociais. Assim, é possível inferir que o homem aprende a ser homem a partir das relações em que está posto. Por conseguinte, pode-se entender que a educação é constitutiva do ser humano e a prática social passa a determinar a forma como a dimensão natural acontece.

A educação tem uma função social central na humanização do homem e em seu desenvolvimento - como homem individual e como espécie. Todas as relações estabelecidas, portanto, fazem com que todos sejam, ao mesmo tempo, educadores e educandos. Assim, o mais subjetivo de nossos sentimentos é produzido socialmente. E, na história - no tempo, como campo do desenvolvimento humano, os homens se humanizam. Afinal, não é, apenas, na experiência direta que são recebidos os elementos de nossa humanização, mas no legado da humanidade em inumeráveis mediações.

Trata-se, então, para se apropriar do objeto dessa reflexão, de delimitar em uma organização social aquilo que é denominado de escola e de 
educação escolar. Não cabe, aqui, recuperar a história da instituição escolar, tampouco identificar as distintas formas de organização da escola em diferentes tempos e espaços, apenas a compreensão de que, dado determinado desenvolvimento humano, tornou-se necessário sistematizar o conhecimento científico, artístico, filosófico, político e pensar nas formas de transmissão desses saberes para as novas gerações.

Para a apropriação de tais saberes, surgiu, historicamente, a necessidade de uma instituição fundamentalmente educativa - a escola, além da necessidade de proceder a um recorte desses saberes - como saberes escolares - e as formas de organizar a sua transmissão como ensino. Do grande conjunto de saberes humanos, portanto, parte deles é objeto de aprendizagem na escola.

O trabalho educativo é o ato de produzir, direta e intencionalmente, em cada indivíduo singular, a humanidade que é produzida histórica e coletivamente pelo conjunto dos homens. Assim, o objeto da educação diz respeito, de um lado, à identificação dos elementos culturais que precisam ser assimilados pelos indivíduos da espécie humana para que eles se tornem humanos e, de outro lado e concomitantemente, à descoberta das formas mais adequadas para atingir esse objetivo (SAVIANI, 1995, p. 17).

Assim, determinado conjunto de conhecimentos deve ser apropriado pelos membros de um grupo social. Mais do que isso, a sociedade deverá definir tal espaço com práticas próprias que garantam essa apropriação. Cabe definir qual conjunto de saberes é esse: assim trata-se dos conteúdos escolares e ainda de definir as formas pelas quais esses saberes serão transmitidos, ou seja, por meio de quais procedimentos ocorrerá sua apropriação. $\bigcirc$ conjunto de saberes que estrutura o processo educativo formal é que corresponde a educação escolar. No que se refere aos saberes escolares, implica compreender que as políticas educacionais orientam a organização de tal processo.

\section{Educação e escola no Brasil}

Na sociedade do capital, toda riqueza humana tornou-se mercadoria bem como os saberes sistematizados - fonte inclusive de toda tecnologia motora da indústria A apropriação dos resultados da indústria e sua oposição 
fundamental, a divisão entre o capital e o trabalho, são evidentemente realizadas de forma desigual na lógica das classes sociais; assim como é desigual a apropriação dos saberes.

A classe trabalhadora é expropriada da riqueza humana, inclusive dos saberes e das artes. Assim, uma sociedade de classes apresenta, necessariamente, o que se convencionou chamar de escola dual. De um lado, as escolas projetadas para a classe proprietária dos meios de produção; de outro, a escola para a classe trabalhadora. Os que podem consumir mercadorias mais elaboradas, ou seja, a classe dominante, acessa uma escola que thes permite a apropriação de saberes mais complexos, mais elaborados, mais desenvolvidos. A arte como conteúdo escolar é uma boa medida dessa escola. Afinal, a condução pela classe dominante, dos processos produtivos e da condução política da sociedade depende de um preparo considerável. A lógica social em que se está inserido distribui, de forma proporcional, às classes o capital e os saberes.

Em nossa sociedade brasileira, contemporânea, de forma geral, a escola particular é aquela que se organiza em diversos níveis de estrutura. Todavia, as mais onerosas são as que oferecem maior universo formativo a seus 112 alunos. Pode fazer parte do "conjunto de mercadorias educacionais adquiridas" a carga horária ampliada, laboratórios, biblioteca, professores altamente capacitados, atividade extraclasse, estudos do meio, e efetivo acesso à cultura, às artes e às ciências. Para os filhos da classe trabalhadora, a escola pública e estatal.

A escola, como tudo no capitalismo, é, necessariamente, de classe, e, à medida que se constitui como pública e estatal é parte do Estado, com todas as decorrências por ser estrutura jurídico-política de determinada formação social. Muitos estudos têm revelado o quanto a escola pública - de forma geral, quando não cumpre seu papel de formadora de sujeitos humanizados - permite a alienação e a precarização, humana necessária à submissão à lógica de classes. Um exemplo é o emblemático trabalho A produtividade da escola improdutiva de Gaudêncio Frigotto (1999).

Em tese, a função da escola na sociedade seria transmitir os saberes sistematizados pelo homem, a ciência, a filosofia, as artes. Ademais, permite a compreensão da prática social, a sociedade e suas relações. Conforme Saviani (1995), isso significa produzir na singularidade do aluno aquilo que a 
humanidade produziv em seu percurso histórico. A forma como isso deve ocorrer exige a elaboração de procedimentos metodológicos, orientados por uma concepção de educação, uma pedagogia.

Tem-se- como constatação - uma escola pública esvaziada de conteúdos e orientada por uma pedagogia que defende tal esvaziamento, visto que está amparada por uma concepção de negação da transmissão em benefício da construção do conhecimento. As pedagogias do "aprender a aprender" se construíram na década de 1980 no Brasil e consolidaram um pensamento teórico e práticas pedagógicas e políticas que seguem orientando a educação escolar até os dias atuais (DUARTE, 200 1). Simultaneamente ao enraizamento dessa orientação teórica e sua política educacional decorrente, há um consenso acerca do fracasso da educação escolar no Brasil.

A filiação teórica do pensamento pedagógico hegemônico em nosso tempo, ao incidir inclusive em escolas da classe dominante, indica negação da aprendizagem como parte de uma relação necessariamente vinculada ao ensino. Não sendo compreendida como relação, ensinar se descola de aprender e a aprendizagem adquire autonomia - como se o ser social fosse um indivíduo autônomo e pudesse aprender fora de uma relação. A origem desse pensamento pedagógico está absolutamente adequada a um momento de reorganização do capital - de suas relações sociais de produção - em que o individualismo é a expressão do homem urbano dos séculos XX e XXI. $\bigcirc$ pragmatismo norte-americano, mais especificamente o pensamento de Dewey e da Escola Nova, produziu o que Duarte (2010, p. 33) chamou de pedagogias negativas: "[...] podem ser consideradas pedagogias negativas, na medida em que aquilo que melhor as define é sua negação das formas clássicas de educação escolar".

Nessa lógica, a escola tem a função de ensinar o método pelo qual se aprende: o aprender a aprender. $\bigcirc$ objeto da educação está dentro do próprio processo, ou seja, o objetivo é sempre o fim ou propósito específico que está imediatamente diante da atenção e que produz o pensamento e a atividade. Esse é o esteio em que se assentam as pedagogias negativas que serão tratadas aqui como pensamento hegemônico em educação.

Lígia Klein (2002) faz um balanço de que - ao final do século XX - se dizia e se fazia na educação na escola pública brasileira, particularmente a alfabetização. Tão pertinente hoje quanto há uma década, o trabalho 
Educação, escola e humanização em Marx, Engels e Lukács

pretende identificar, no discurso pedagógico, a constatação dos problemas que fazem da escola um rotundo fracasso em sua tarefa de permitir à classe trabalhadora o acesso aos conhecimentos sistematizados. A autora faz um representativo levantamento do discurso que constata o fracasso da escola pública. Ela destila alguns elementos constantes na indicação da superação do estado de coisas - amparadas pela apologia do novo e busca identificar a fragilidade desse percurso - que, no limite, confirma a distribuição desigual dos saberes na sociedade de classes. Como parece um estudo emblemático, procurar-se-á parafrasear a autora, visando apresentar seu caminho analítico, por entender que é um trabalho claro e preciso, além de absolutamente adequado aos pressupostos e fundamentos da compreensão do homem e do mundo aqui apresentados.

\section{A educação escolar para o enriquecimento humano}

Klein (2002) apresenta um recorte denominado de literatura pedagógica que constata a crise na educação brasileira, o fracasso escolar, a evasão e a repetência que poderia, hoje, somar ao volume de análises e publicações acerca das notas e números dos índices nacionais e internacionais que medem o desempenho escolar tanto de crianças como de jovens brasileiros. Os autores a que Klein se refere são relevantes e referenciais nesse debate. Em geral, o discurso - bastante homogêneo - reivindica uma pedagogia para as classes populares. Isso indica uma consciência de classe orientadora desse discurso e um anunciado compromisso com a escola pública. Ademais, Klein identifica uma relação com o conjunto categorial do marxismo: história, luta de classes e totalidade, porém a raiz desses termos está absolutamente descolada da concepção ontológica - materialista, histórica e, sobretudo, dialética. Além dos termos, a autora revela o quanto a compreensão é a-histórica e liberal, além de idealista.

É preciso deixar de ensinar. Assim, o professor precisa ser um facilitador, pois aprender é algo individual. No limite, é necessária uma intervenção não invasiva, que respeite o limite, o interesse, enfim, a expectativa do aluno. Ele é o centro do processo, sobretudo, por não ser uma relação, ele é o todo. Nessa direção, Klein reafirma, no interior dessa crítica, como ocorre um esvaziamento da compreensão ontológica da educação e da materialidade da 
construção do homem no interior das relações sociais, manifestada sob a forma de crítica à escola tradicional.

A denúncia é sistematizada em quatro pontos interligados, mas expostos de forma bastante didática A escola tradicional não considera o aluno real, mas uma abstração idealizada. Ela fragmenta o real e lida com conhecimento pronto, acabado, desvinculado da realidade e relega o aluno a uma condição passiva.

Contrapondo-se a tais pontos, se propõe o aluno concreto, a busca da totalidade, a identificação de conteúdos que sejam de interesse dos alunos e a construção do saber pelo aluno, agente de seu processo de conhecimento. A desmontagem do discurso pela análise cuidadosa de Klein (2002) revela o quanto há de pragmatismo filosófico nas soluções indicadas e mais, o quanto o aparente discurso materialista histórico e dialético se revela, no limite, como individualismo liberal.

reducionismo revela-se ao ser identificado o aluno concreto não como o ser social posto na totalidade das relações sociais de produção, mas vinculando-o a uma comunidade. Mas, o gueto, o local, o espaço ao entorno são suficientes para determinar a concretude do aluno que, em vez de ganhar o peso do ser do seu tempo, limita-se a um espécime pontual enclausurado em um cotidiano e desenho geográfico bastante limitado.

De fato, as considerações que completam essa afirmação dão margem à compreensão de que existe uma realidade do aluno que se processa à margem de outra realidade que não é a dele. A realidade fica assim, fragmentada em tantas partes quanto forem os ambientes em que as pessoas vivem, e se supõe que cada um desses fragmentos tem, no seu próprio interior, os elementos que o determinam. Mais uma vez, aqui, abstraem-se as relações mais amplas que fazem com que, para além das diferenças individuais, locais, regionais, todos os homens se encontrem e se reconheçam como homens de uma mesma sociedade (KLEIN, 2002, p. 53).

A compreensão da totalidade como contraposição do real, por mais legítima que se apresente, revela-se como arremedo ao identificar uma totalidade em si fragmentada - a totalidade do aluno e a totalidade do conteúdo. A totalidade do aluno se remete a um individualismo extremado - a ideia do aluno como um todo, como um indivíduo único - sua individualidade, sua particularidade, seu ritmo, seu interesse, seus desejos, seus medos, seus sonhos, 
absolutamente descolados da determinação social de cada uma dessas individualidades e, como decorrência, a realidade, também, se fragmenta - e com ela os conteúdos. A saída indicada pelo pensamento pedagógico em questão é a soma das partes, o multidisciplinar, o multicultural, a integração das partes.

Anestesiando dessa forma o centro nervoso que unifica todos os membros, só resta aos autores clamar para que cada membro, com uma vida que the é própria, se reintegre ao corpo, relacionando-se não mais a partir daquele centro - agora subjugado - mas, a partir de uma ligação mecânica com os outros membros (KLEIN, 2002, p. 611 .

A postura que denuncia os saberes prontos e acabados caracteriza desprezo pela síntese histórica dos saberes acumulados enquanto riqueza humana, sobretudo, a relativização da ciência. A identificação dos discursos científico, filosófico e artístico - como saberes distantes da realidade dos alunos - e reafirmados como desinteressantes e descolados do seu universo de interesses, descarta aquilo que seria o objeto em si da escola - sua função social por excelência. Em seu lugar, a realidade do aluno no limite da empi-

116 ria, do senso comum, da repetição de elementos, das práticas e percepções que crianças e jovens acessam em seu cotidiano - sem a menor necessidade de irem à escola. A construção conceitual - base da elaboração do pensamento - limita-se a conceitos já construídos e simpáticos, porque são familiares. Afinal, a autora afirma a impossibilidade de haver interesse por algo que não se conheça. Nesse movimento empobrecedor, há uma apologia dos sentidos, supervalorização da experiência individual e particular, e, ainda a afirmação da miséria e da expropriação a que estão submetidos os alunos das classes populares.

Causa no mínimo estranheza a contradição que salta a vista nessas proposições: por um lado declara-se a intenção de uma 'educação em favor das classes populares'; de outro, respeita-se exatamente aquilo que, nos alunos das classes populares, é expressão da expropriação. Se estamos convencidos de que a sua fonte de vida é a condição de todo Bem e Verdade, não se explica nossa luta por mudanças sociais. Penso ser necessário invertermos o eixo de nossas preocupações: é preciso respeitar o homem, opondo-se às condições reais de vida que o condicionam a um estado de miséria, ignorância, doença etc (KLEIN, 2002, p. 88). 
Se a escola não se compromete com o enriquecimento humano no sentido da humanização aqui defendido, no limite, opera a expropriação, contribui com o movimento próprio da lógica intrínseca ao modo de produção capitalista que é a alienação da classe trabalhadora. Essa questão recoloca o grande debate acerca de a escola ser espaço de dominação ou de libertação de classe. Na direção que se pretende argumentar, ela é, na sua promessa, espaço de humanização e, no movimento da luta de classes, é fundamental perseguir, exigir, lutar para que ela cumpra esse papel.

A escola precisa garantir o acesso das classes trabalhadoras aos conteúdos sistematizados pela humanidade; como os sujeitos da escola pública - alunos e professores - são oriundos dessa mesma classe, é imperativo ter clareza das pedagogias escolhidas como orientadoras das práticas educativas. A sedução do discurso pedagógico do "aprender a aprender" que se enraíza na crítica acerca da falência da escola tem uma direção política. Assim, urge perguntar a quem serve essa pedagogia, ou como fez Klein (2002): Quem tem medo de ensinar?

Portanto, o conjunto de análises críticas e a contundência do fracasso da escola, sobretudo a pública, elaboram a demonização da transmissão. Nesse sentido, entende-se aqui transmissão, socialização, comunicação. $\bigcirc$ termo transmissão é, de certa forma, proibido no interior do debate pedagógico como a constatação do desrespeito ao outro, da autoridade da escola tradicional e da empáfia do detentor do saber que oprime e diminui o seu aluno. Desse universo, muitas vezes, real na escola tradicional, demonizou-se a essência da escola e sua função, contudo, o papel social do professor se perdeu no ar. Por isso, ele procura, constrangido, seu lugar como facilitador, colaborador, mediador, porém não mais como transmissor de saberes.

Dessa forma, chega-se ao último ponto levantado por Klein, se o professor não é o detentor de saberes e não the cabe ensinar, é mister que o aluno seja senhor do seu processo de aprendizagem, desde a determinação dos conteúdos que the apeteçam até as formas e práticas do fazer escolar. A-histórico, individualista e com limitada compreensão das relações que o cerca, o aluno é o centro de um processo que começa e termina em si mesmo.

A relação rompida - ensinar/aprender é substituída pela aprendizagem em si, sozinha, alheada e se daria pela construção do conhecimento. 
A preocupação perfeitamente justificada, de que, no ato de ensinar, aquele que ensine não o faça de maneira que inviabilize situações em que o aprendiz desenvolva reflexões, compare, analise, conclua, em outras palavras compreenda as relações implícitas num dado objeto de conhecimento, tem assumido um caráter de tal forma dogmático, que praticamente anula os outros elementos implicados na aprendizagem: o professor e o conteúdo (KLEIN, 2002, p. 811 .

Klein apresenta uma rica e pertinente análise, sempre partindo de um conjunto de falas que revelam as escolhas, as quais - de forma geral - orientaram a organização da escola pública quanto aos conteúdos e procedimentos em um denuncismo que não tem levado a alterações no quadro de fracasso quando se compreende que o papel da escola é o de dar acesso aos saberes sistematizados. Defende, ainda, que a escola e seus professores ensinem.

\section{Educação, escola e o "aprender a aprender"}

Nessa mesma linha da compreensão do consenso pedagógico

118 atual expresso por construções analíticas e políticas educacionais, procurar-se-á seguir outro estudioso da pedagogia no Brasil, Newton Duarte, autor que tem construído um caminho de análise que se desenha como militância em defesa da Pedagogia Histórico-Crítica ${ }^{5}$ na interface com a Psicologia Histórico-Cultural ${ }^{6}$. Essa perspectiva pedagógica é legatária do movimento de incidência do pensamento marxista na produção educacional brasileira entre os anos 1970 e 1980, sobretudo por indução do professor Dermeval Saviani, à época, no Programa de Pós-Graduação da Pontifícia Universidade Católica - PUC, de São Paulo, conforme Yamamoto (1998, p.23).

Assim, nessa perspectiva, a compreensão de que a socialização dos conhecimentos científicos, filosóficos e artísticos é direito humano, e a classe trabalhadora não os acessa de forma plena é reafirmada pela lógica orientadora de a escola pública estar contaminada pelo construtivismo, as chamadas pedagogias do aprender a aprender que limitam seu acesso ao conhecimento, condição de compreensão do real para a superação da alienação - e, portanto, central na luta de classes. Afinal, a "[...] postura crítica sobre a realidade permite identificar o percurso histórico de superação"(DUARTE, 2000, p. 103). 
A defesa que Duarte faz da pedagogia histórico-crítica se ancora na ideia de que a educação é um meio para a superação da alienação e esta, a condição da efetivação do trabalho educativo - indica que, assim como a produção da riqueza no capitalismo ganha contornos abissais, tal riqueza vem acompanhada dialeticamente do empobrecimento e esvaziamento do trabalho humano. Ao manusear um smartphone, tem-se à disposição a síntese de formas extremamente elaboradas de compreensão do mundo que permite produzir um aparelho para comunicação que acesse lugares remotos, imagens, pessoas, e os mais variados serviços - enfim, síntese de riqueza e desenvolvimento humano. A posse de tamanha riqueza pode expressar um conjunto de seres humanos fragilizados e incapazes de compreender o funcionamento do aparelho, sua estrutura, os métodos de transmissão das informações e, até mesmo, as informações em si que possam ser acessadas.

Essa imagem é emblemática devido à contradição entre humanização e desumanização. A hipótese central de Newton Duarte - com base nas formulações de Saviani - é a de que o empobrecimento humano não é expressão única do capitalismo, mas a contradição entre empobrecimento e enriquecimento. A questão central é que essa não é uma dicotomia - ainda que se expresse na oposição das classes sociais - mas um movimento dialético. Afinal, a raiz de toda realização capitalista se inicia nas mãos dos trabalhadores e se encerra na apropriação pela classe dominante da riqueza produzida.

O capitalismo tem sido a forma de organização social que alcançou a maior eficiência - tanto na produção da riqueza quanto na sua expropriação. No movimento dialético de produção do trabalho educativo, tem-se a certeza de que a escola pública brasileira é altamente capaz de produzir a alienação e a identifica em um vasto conjunto de análises e pesquisas acerca de procedimentos pedagógicos e políticas educacionais - a eficiência da sociedade burguesa em tornar a escola um espaço de vazios e incompetências. Ocorre que a lógica burguesa se apropria desse espaço e - com absoluta consciência do risco que seria permitir à classe antagônica acesso aos saberes elaborados e desenvolvidos - imprime à escola o papel de alienadora e disciplinadora.

movimento contrário que se coloca para os trabalhadores é lutar pela plena apropriação dessa riqueza e com ela a ampliação da humanização do homem. Evidentemente, não se trata de uma apropriação direta da riqueza produzida pelo capitalismo (tanto material como intelectual). Trata-se de uma escola que seja capaz de permitir a compreensão do mundo além da 
mercadoria e da propriedade privada que suponha uma sociedade em que o indivíduo apreenda sentidos ou conteúdos, que possa se entender pleno no coletivo e que sua realização seja a realização do outro, conforme Marx (1982, p. 5): "De cada um segundo as suas capacidades, a cada um segundo as suas necessidades!".

Para que se possa construir tal sociedade, é fundamental que se detenha o domínio do acúmulo produzido na sociedade capitalista para que se possa proceder à superação - no movimento dialético de negação por superação. A transformação ocorre, necessariamente, a partir do que se tem - afinal, se está considerando o pressuposto materialista e sobretudo histórico; nessa hipótese, o novo só pode nascer do velho.

Nesse processo, essas forças produtivas terão que passar por profundas transformações, pois muitas de suas atuais características não serão adequadas a uma situação em que os objetivos da produção material e não material não sejam mais aqueles determinados pela lógica econômica capitalista. Ocorre que as transformações radicais das forças produtivas não acontecerão a partir do nada, mas sim a partir da apropriação do que já existe (DUARTE, 2014, p. 37).

Importa ressaltar na argumentação de Duarte (2014) que a superação da alienação é necessária para que se possa socializar a riqueza humana - a "realização plena da educação escolar não será alcançada na sociedade capitalista". Isso não exime a pedagogia comprometida com a luta social de construir, cotidianamente, as condições para a humanização; e ainda que muitas pedagogias progressistas pretendam fazê-lo, a alternativa que desconsidera a apropriação dos acúmulos da ciência, tecnologia, filosofia e arte permite um caminho contrário daquele que defende. Nesse ponto, encontra-se o volume da produção de Duarte na crítica às chamadas pedagogias do "aprender a aprender". Entre tais equívocos, sobressai aquele que entende ser necessário aproximar a escola da vida.

Quanto mais as ações realizadas no interior das escolas se assemelham ao cotidiano da sociedade capitalista, mais alienante se torna a educação escolar. Ao contrário das acusações feitas à escola ao longo do século XX, de distanciamento em relação à vida, minha interpretação é a de que à medida que a escola foi se universalizando, a burguesia e seus aliados foram pondo em ação 
mecanismos que aproximam as atividades educativas escolares às formas mais alienadas que a vida assumiu na sociedade capitalista (DUARTE, 2014, p. 38).

Em "Vygotsky e o 'aprender a aprender': crítica às apropriações neoliberais e pós-modernas da teoria vygotskyana" (DUARTE, 2001 a), o caminho percorrido pelo autor pretende refletir, analisar e denunciar a diluição de teorias revolucionárias em educação em meio a formulações conservadoras na compreensão da educação escolar e da relação entre ensinar e aprender.

A obra se inicia com uma leitura de documentos importantes e orientadores de políticas educacionais como o Relatório para a Organização das Nações Unidas para a Educação, a Ciência e a Cultura (Unesco) da Comissão internacional sobre Educação no Século XXI e os Parâmetros Curriculares Nacionais. Logo, isso indica que mais que se apropriar de conhecimentos e da ciência, o papel da educação escolar é estimular os estudantes a conhecer e desenvolver métodos para construir conhecimento, como atividade principal e capacitadora para os desafios do século XXI. Ocorre que, orientada pela ideologia pós-moderna e neoliberal, essa hipótese se reafirma na negação da transmissão de conteúdos e na condenação dos acúmulos da ciência moderna.

Tal caminho analítico permite que o autor, no terceiro capítulo, recupere elementos de sua obra A Individualidade para Si (DUARTE, 2012) em que ocorre um esvaziamento da individualidade no mundo capitalista - e o ser social vem substituindo a sociabilidade pela mediação da mercadoria. Essa, como explica Marx, assume dimensões humanizadas - em sua reificação - na mesma medida em que os seres humanos se desumanizam. $\bigcirc$ mesmo movimento ocorre na escola - condições abstratas de aprender substituem conteúdos científicos e artísticos. Aprender a aprender é muito mais desejável do que saber história, matemática ou dominar a língua portuguesa.

Duarte segue afirmando a necessária retomada de Vygotsky pelo pensamento materialista histórico e dialético e de sua rigorosa vinculação a Marx e direciona os últimos capítulos a defender a distinção entre Vygotsky e outros autores. Inicialmente, os pensadores da chamada psicologia sócio-histórica alertam para a necessária revisão das traduções de seus escritos. Na sequência, focaliza Piaget quando afirma o radical antagonismo entre esses autores, identificando-os com propostas pedagógicas, vinculadas ao projeto capitalista de mundo e de escola em oposição ao projeto de mundo socialista. 
Neste texto e na importante obra "A anatomia do homem é a chave da anatomia do macaco: A Dialética em Vygotsky e em Marx e a questão do saber objetivo na educação escolar", Duarte (2000) recupera o "Manuscrito de 1929" de Vygotsky, para afirmar que

[...] a relação filogênese-ontogênese no desenvolvimento orgânico é distinta da mesma relação no desenvolvimento cultural: enquanto o embrião humano se desenvolve sem interagir com o organismo adulto, o desenvolvimento cultural da criança só ocorre por meio da interação com o adulto, isto é, com o ser mais desenvolvido (DUARTE, 2000, p. 1).

A relação entre o mais desenvolvido e o menos desenvolvido como mote do desenvolvimento tem por fundamentação o estudo de Marx sobre a anatomia de o homem constituir a chave da anatomia do macaco. Nessa argumentação, ele recupera as relações entre a dialética em Vygotsky e em Marx. De forma didática, o autor reconstrói metodológica e epistemologicamente a compreensão da dialética nos autores. Duarte defende a tese de que "a psicologia vygotskyana fornece apoio a uma pedagogia que valorize a transmissão das formas mais desenvolvidas do saber objetivo produzido pela humanidade" (DUARTE, 2000, p. 1).

A afirmação contundente desses estudos é a de que a escola cumpre um papel que, efetivamente, contribui com o processo de construção do homem mais humanizado quando possibilita que os alunos aprendam conteúdos da ciência, filosofia e das artes. Dessa recuperação dos conteúdos das relações, Newton recupera e reafirma - na defesa do debate acadêmico, instaurado entre estudiosos da educação que apresentam como marxistas - a concepção de trabalho educativo.

A definição de trabalho educativo proposta por Saviani não é outra coisa senão uma síntese das possibilidades máximas de educação que se constituíram historicamente e se apresentam na sociedade contemporânea de maneira extremamente contraditória e heterogênea. É uma definição ao mesmo tempo histórica, ontológica, ética e política (DUARTE, 2014, p.42).

A máxima de Marx e Engels, - presente no início deste texto - de que o trabalho produziu o homem é que essa é uma atividade humana e 
humanizadora e, por excelência, deve ser retomada na conclusão. A proposição de Duarte pretende reafirmar que a superação do capitalismo, de forma alguma, implicaria a superação do trabalho - mas do trabalho na lógica capitalista, produtor de mercadorias e de desumanização - em todas as suas dimensões na medida em que é a raiz de toda alienação.

Dessa forma, pretende-se colocar como questão a compreensão do papel da escola na luta de classes - suas contradições e possibilidades. Isso só faz sentido se colocar como questão o entendimento de que no movimento da dialética - movimento de que contém a contradição, mas também a síntese - não é possível se pensar a escola como absolutamente reprodutora ou transformadora, mas, necessariamente, uma tensão constante entre esses dois polos. Ainda que, no momento histórico atual, a escola se apresente como muito mais alienadora que transformadora, sempre constituiv espaço da tensão determinadora das relações sociais de produção no capitalismo - a tensão entre capital e trabalho.

E, se é tensão, há o espaço para que a escola seja instrumento e espaço de resistência e de luta na medida em que se permita a apropriação dos saberes mais desenvolvidos que os homens puderam sistematizar como riqueza humana, promotora de mais desenvolvimento e como riqueza de todos

\section{Notas}

1 Aqui nos referimos ao estudo clássico "A origem das espécies" de Charles Darwin, 1859.

2 Debate central da obra de Lukács é a afirmação materialista do pensamento como ontologia em oposição às perspectivas do pensamento filosófico que indicam diferentes formas de autonomia do pensamento em relação à matéria.

3 Este personagem é o protagonista do texto literário "O livro da selva" de RudyardKipling, 1894.

4 Em referencia à obra LUKÁCS, G. Estetica - laPeculiaridad de lo Estetico. Barcelona: Grijalbo, 1966. (4 v).

5 Pedagogia histórico-crítica - pedagogia que se apresenta como materialista histórica e dialética, vinculada à psicologia histórico-cultural e proposta e sistematizada, em suas linhas gerais por Dermeval Saviani

6 Psicologia Histórico-Cultural: A teoria histórico-cultural tem suas origens nos estudos de Lev Semenovich Vygotsky (1896-1934). 


\section{Referências}

DUARTE, Newton. A anatomia do homem é a chave da anatomia do macaco: a dialética em Vygotsky e em Marx e a questão do saber objetivo na educação escolar. Educação \& Sociedade, Campinas, v. 21 , n. 71, p. 79-1 15, jul. 2000. Disponível em: http://dx.doi. org/10.1590/S0101-73302000000200004. Acesso em: 26 ago. 2014.

As pedagogias do aprender a aprender e algumas ilusões da assim chamada Sociedade do Conhecimento. Revista Brasileira de Educação, Rio de Janeiro, n. 18, p. 35-40, set. 2001.

Vygotsky e o "aprender a aprender": crítica às apropriações liberais e pós-modernas da teoria vygotskyana. 2. ed. Campinas: Autores Associados, 2001 a.

Pela superação do esfacelamento do currículo realizado pelas pedagogias relativistas. jul. 2008. Disponível em: http://www.gestaoescolar.diaadia.pr.gov.br/arquivos/ File/sem_pedagogica/fev_2010/pela_superacao_esfacelamento_curriculo.pdf. Acesso em: 1 set. 2014 .

debate contemporâneo das teorias pedagógicas. In: MARTINS, Ligia Márcia; DUARTE, Newton (Org.). Formação de professores: limites contemporâneos e alternativas necessárias. São Paulo: Cultura Academica, 2010.

Lukács e Saviani: a ontologia do ser social e a pedagogia histórico-crítica. In: SAVIANI, Dermeval; DUARTE, Newton (Org.). Pedagogia histórico-crítica e a luta de classes na educação escolar. Campinas: Autores Associados, 2012. (Coleção Polêmicas do Nosso Tempo).

A pedagogia histórico-critica no âmbito da história da educação brasileira. In: PINHEIRO, Antonio Carlos Ferreira, CURY, Claudia Engler e ANANIAS, Mauricéia (Org.). Histórias da educação brasileira: experiências e peculiaridades. João Pessoa: Editora da UFPB, 2014.

ENGELS, Friederich.Ludwig Feuerbach e o Fim da Filosofia Clássica Alemã. In: Obras Escolhidas. São Paulo: Alfa-Ômega, s/d. (v. 3).

Sobre o papel do trabalho na transformação do macaco em homem. 3. ed. São Paulo: Global, 1986.

FRIGOTTO, Gaudêncio. A produtividade da escola improdutiva. 5. ed. São Paulo: Cortez, 1999. 
KLEIN, Lígia Regina. Alfabetização: quem tem medo de ensinar? 4. ed. São Paulo: Cortez; Campo Grande: Editora da Universidade Federal do Mato Grosso do Sul, 2002.

Fundamentos para uma proposta pedagógica. Disponível em: http://www.gestaoescolar.diaadia.pr.gov.br/arquivos/File/otp/docs_pdf/fundamentos_prop_ped.pdf. Acesso em: 28 ago. 2014.

KIPLING, Rudyard. O livro da selva. Tradução Vera Karam. Porto Alegre: L\&PM,2005.

LUKÁCS, Gyogy. Estetica la peculiaridad de lo estetico. Barcelona: Grijalbo, 1966.

As bases ontológicas do pensamento e da atividade do homem. Tradução Carlos Nelson Coutinho, São Paulo: Livraria Editora Ciências Humanas, 1978. Disponível em:http://moviments.net/espaimarx/docs/8 1 8f4654ed39a lc l 47d le5 laO0ffb4cb. pdf. Acesso em: 26 ago. 2014.

MARX, Karl. Crítica ao programa de Gotha. Obras Escolhidas, Lisboa: Edições Progresso, 1982. Disponível em: http://www.marxists.org/portugues/marx/1875/gotha/gotha. htm. Acesso em: 26 ago. 2014.

MARX, Karl; ENGELS, Friederich. A ideologia alemã. 4. ed. Tradução José Carlos Bruni e Marco Aurélio Nogueira. São Paulo: Hucitec, 1984.

MARX, Karl. O capital. 3. ed. Tradução Regis Barbosa e Flávio Kothe. São Paulo: Nova Cultural, 1988

MUCCl, Latuf I. Da consciência estética. Revista Educação em Questão, Natal, v. 7, n. 1-2, p. 124-134, jan./dez. 1997.

PAULO NETTO, José. BRAZ, Marcelo. Economia política: uma introdução crítica. São Paulo: Cortez, 2006.

SAVIANI, Dermeval. Pedagogia histórico-crítica: primeiras aproximações. 5. ed. São Paulo: Autores Associados, 1995.

YAMAMOTO, Oswaldo Hajime. O aporte marxista na educação brasileira no contexto da resistência e da transição democrática. Revista Educação em Questão, Natal, v. 8, n. 1, p. 15-32, jan./jun. 1988.

Profa. Dra. Liliam Faria Porto Borges Universidade Estadual do Oeste do Paraná | Campus de Cascavel | Paraná Programa de Pós-Graduação em Educação 
Artigo

Educação, escola e humanização em Marx, Engels e Lukács

Centro de Educação, Comunicação e Artes Grupo de Pesquisa em Políticas Sociais | GPPS

E-mail |liliam.borges@unioeste.br

Recebido 29 maio 2017

Aceito 9 jun. 2017

126 